\title{
DISCOURSE MARKERS IN PEER REVIEWS OF ACADEMIC ESSAYS BY FUTURE TEACHERS OF ENGLISH AS A FOREIGN LANGUAGE
}

\author{
OLEKSANDR KAPRANOV ${ }^{1}$
}

\begin{abstract}
This article presents and discusses a quantitative investigation of discourse markers (further - DMs) in the corpus of peer reviews of academic essays in didactics written by a group of future teachers of English as a Foreign Language (EFL). In total, 12 future EFL teachers at an intermediate level of EFL proficiency (henceforth - participants) took part in the study. The participants were instructed to form dyads and write peer reviews of each other's academic essays on a range of topics in EFL didactics. Two corpora were used in the study, the corpus of the participants' academic essays in EFL didactics and the corpus of peer reviews thereof. The corpora were analysed using WordSmith (Scott 2008) in order to establish the frequencies of the use of DMs per 1000 words. The results of the quantitative analysis of the corpora indicated that the participants employed a repertoire of stylistically neutral DMs in their peer reviews that was quantitatively similar to that of the academic essays. These findings will be further discussed in the article.
\end{abstract}

Keywords: Academic writing; discourse markers; EFL; peer review.

\section{Introduction}

This article presents and discusses a quantitative study of discourse markers (henceforth DMs) in the corpus of peer reviews of academic essays in didactics written by a group of future teachers of English as a Foreign Language (EFL). Academic essays in EFL didactics can be argued to conform to the style of academic writing in English (Povolná 2013; Jančaříková et al. 2020). Academic writing is conceptualised in this study as a complex skill that develops through an EFL learner's exposure to genre conventions and practices that are associated with academic discourse (Hyland 2008; Hryniuk 2018: 621; Jiang \& Hyland 2020). Presumably, the genre-appropriate use of DMs is one of those conventions

1 NLA University College, campus Oslo. PBox 7153, St. Olavs plass. 0130 Oslo, Norway. oleksandr.kapranov@nla.no 
in academic writing that EFL learners should master (Ramos 2015). In the present study, DMs are defined in accordance with a widely quoted definition proposed by Fraser (1999):

\begin{abstract}
Whether they are called discourse markers, discourse connectives, discourse operators, or cue phrases (I shall use the term 'discourse marker'), the expressions under discussion share one common property: they impose a relationship between some aspect of the discourse segment they are a part of, call it S2, and some aspect of a prior discourse segment, call it S1. In other words, they function like a twoplace relation, one argument lying in the segment they introduce, the other lying in the prior discourse. (Fraser 1999: 938)
\end{abstract}

Employing this definition as a point of departure, the study seeks to explore the frequency of DMs in the corpus of peer reviews of academic essays in EFL didactics written by a group of future EFL teachers (henceforth participants). The approach to peer review in this study follows that of Vorobel \& Kim (2014), who regard it as a process of "collaborative activity of students who, while analyzing a peer's writing, providing feedback on it, and negotiating the meaning, develop critical thinking skills in English" (Vorobel \& Kim 2014: 699). It should be noted that Vorobel \& Kim's approach to peer review writing is echoed by Crawford, McDonough \& Brun-Mercer (2019), who suggest that

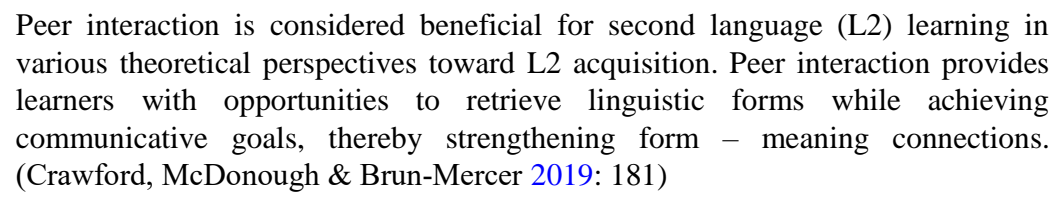

Whereas "peer review as a pedagogical activity has received increasing attention" (Hu \& Lam 2010: 372), research studies that investigate the use of DMs in peer review writing are still underrepresented. The present study seeks to address this issue by means of a quantitative analysis. This article is structured as follows. First, recent research on DMs in academic writing by EFL students will be given in Section 1.1. Second, an outline of previous studies associated with peer review writing in EFL contexts will be provided in Section 1.2. Then, the present study will be introduced and discussed in Section 2. Finally, the article will be concluded with a summary of major findings and their linguo-didactic implications (see Section 3).

\title{
1.1. Recent research on DMs in academic writing by EFL students
}

There is a wealth of recent studies that investigate the use of DMs in academic writing by EFL students (Chen 2006; Šimčikaite 2012; Povolná 2013; Unaldi 2013; Babanoğlu 2014; Appel \& Szeib 2018; Gil 2018; Ziyagham \& Simin 2018; 
Bax, Nakatsuhara \& Waller 2019; Hayisama, Shah \& Adnan 2019; Lotfi, Sarkeshikian \& Saleh 2019; Sato 2019). DMs in academic writing by EFL student writers are approached through the lenses of frequency (Chen 2006; Unaldi 2013; Gil 2018; Bax, Nakatsuhara \& Waller 2019), variation (Povolná 2013; Sato 2019), coherence (Appel \& Szeib 2018), culture (Hayisama, Shah \& Adnan 2019; Lotfi, Sarkeshikian \& Saleh 2019), and genre (Šimčikaitè 2012; Babanoğlu 2014; Ziyagham \& Simin 2018).

The approach that is common to the studies conducted by Chen (2006), Gil (2018), Unaldi (2013), and Bax, Nakatsuhara \& Waller (2019), and consists in establishing the frequency of the use of DMs in EFL students' writing. In particular, the study by Chen (2006) aims at elucidating the frequency of the use of DMs as connectors by means of contrasting two corpora, e.g., the corpus of scientific articles written by English L1 speakers and the corpus of scientific papers written by advanced EFL students from Taiwan. Chen (2006) has established that the EFL students in the study over-use DMs. In addition, certain DMs, for instance, besides and therefore, respectively, are used inappropriately by some of the EFL student writers. Similarly to Chen (2006), the over-use of DMs is reported in the study conducted by Bax, Nakatsuhara \& Waller (2019). The data analysis in their study reveals that less proficient EFL student writers employ more DMs in contrast to proficient EFL student writers. Bax, Nakatsuhara \& Waller (2019) report that the latter group uses a significantly wider range of DMs. The findings in the aforementioned studies are in line with a recent investigation conducted by Gil (2018), who indicates that Spanish L1 EFL student writers either over-use English DMs in their academic writing or appear to underutilise them (Gil 2018). Analogously to Bax, Nakatsuhara \& Waller (2019), the over-use of the English DMs has been established by Unaldi (2013). By means of conducting a frequency count in the corpus of texts written by Turkish L1 EFL students, Unaldi (2013) observes that the students' use of the DMs I think and in my opinion is statistically significant.

The approach to the analysis of DMs in the studies by Povolná (2013) and Sato (2019), respectively, is associated with the variation in the use of DMs. Specifically, Povolná (2013) aims at establishing the difference in the use of causal and contrastive DMs seen though the lenses of variation. By means of compiling and analysing the corpus of diploma theses written by Czech L1 and German L1 EFL students, Povolná (2013) concludes that whereas there is a certain level of variability between the Czech L1 and German L1 cohorts, they both are characterised by several common typical problems when using DMs to express causal and contrastive relations in academic texts. Amongst the common problems Povolná (2013) points out to the students' tendency to over-use such DMs as because, since, and as. In particular, the latter DM is reported to be over-used in the theses written on the topics in literature and EFL didactics (Povolná 2013). 
Analogously to Povolna (2013), the variation in the use of DM is explored in the study conducted by Sato (2019), who examines the functional variability of the DM so in the corpus of essays written by English L1 student writers and their Japanese L1 counterparts. Sato (2019) suggests that whilst English L1 student writers use the DM so strategically in stance-taking, Japanese L1 EFL student writers use so as a connective marker with resultative meaning and not as a discursive means of projecting stance and assertion. It should be noted that both Povolná (2013) and Sato (2019) concur in their conclusions that DMs could be regarded as a means of achieving coherence and cohesiveness in the text.

The aforementioned conclusions drawn by Povolná (2013) and Sato (2019) are in harmony with the study by Appel \& Szeib (2018), where DMs are argued to be linking devices that are employed by EFL student writers to facilitate text coherence. Appel \& Szeib (2018) investigate that assumption in a learner corpus of 150 argumentative essays written by Arabic L1, Chinese L1, and French L1 EFL student writers. By means of combining quantitative and qualitative measures, Appel \& Szeib (2018) have established that additive (e.g., also) and contrastive (e.g., however) DMs are frequently used in the participants' academic writing.

The approach towards DMs as rhetorical devices associated with an EFL student's culture is explored by Hayisama, Shah \& Adnan (2019), and by Lotfi, Sarkeshikian \& Saleh (2019). Hayisama, Shah \& Adnan (2019) indicate that Thai L1 and Malay L1 EFL students share similar rhetorical preferences in terms of the use of DMs in academic writing. The findings in Hayisama, Shah \& Adnan (2019) reveal the prevalence of DMs as hedges, which implies that Thai L1 and Malay L1 EFL student writers prefer a tentative and indirect manner of academic writing. Given that the occurrence of attitude DMs and engagement DMs in the study is not significant, Hayisama, Shah \& Adnan (2019) suggest that Thai L1 and Malay L1 EFL student writers' rhetorical tone of academic writing is less dialogic and distant. The authors conclude that from a sociocultural perspective, the aforementioned distribution of DMs in academic writing by Thai L1 and Malay L1 EFL student writers is associated with the South-East Asian style of communication, which is typically regarded as indirect and tentative (Hayisama, Shah \& Adnan 2019). In the study conducted by Lotfi, Sarkeshikian \& Saleh (2019), DMs are analysed within the cultural and discursive space of argumentative essays written by Persian L1 and Chinese L1 EFL university students. Lotfi, Sarkeshikian \& Saleh (2019) argue that the use of DMs is associated with the rhetorical patterns in two different cultural settings. Specifically, their results indicate that there are significant differences between Persian L1 and Chinese L1 EFL student writers as far as the use of DMs is concerned.

In addition to the previously mentioned research themes, there are several fairly recent studies that focus on the genre-related and genre-appropriate use of 
DMs in academic writing by EFL student writers (Šimčikaite 2012; Babanoğlu 2014; Ziyagham \& Simin 2018). These studies aim to elucidate whether EFL student writers use DMs that are associated with the formal (e.g., the DM hereby), neutral (e.g., the DM and), or informal (e.g., the DM wow) registers of the English language. From the vantage point of genre-appropriateness and register, Šimčikaite (2012) has found that EFL student writers whose L1 is Lithuanian make frequent use of the DMs that are related to the informal register of English. Based upon this finding, Šimčikaite (2012) argues that EFL student writers seem to experience register confusion. This is manifested by the concurrent use of informal and formal DMs in one piece of academic writing. Šimčikaite (2012) posits that register confusion is suggestive of the insufficient EFL writing skills as well as a lack of awareness of the formal register of the English language, which is typically expected to be used in academic writing.

The findings reported by Šimčikaite (2012) are echoed in the corpus-assisted study conducted by Babanoğlu (2014). She indicates that Turkish L1 EFL student writers produce academic writing that appears to be marked by the presence of the informal DMs (e.g., I mean, kind of, etc.). Apparently, the participants in the study mix informal and formal DMs in English due to register confusion (Babanoğlu 2014). Whilst the notion of register confusion is not extensively expanded upon by Šimčikaite (2012), it is elaborated by Babanoğlu (2014), who explains it by means of evoking the communicative approach towards EFL teaching and learning. In this regard, she posits that

\footnotetext{
Course textbooks that take a communicative approach as the major theoretical background for grammar instruction may promote confusion between written and spoken registers among learners by focusing on a communication-oriented task. Correlatively, learners may overgeneralize the communicative aspects in their writing by using lexical items or expressions in inappropriate contexts to overcome the difficulties of using the target language. (Babanoğlu 2014: 192).
}

In addition to register confusion due to the communicative methods of EFL instruction, Babanoğlu (2014) attributes a relatively frequent use of the informal DMs to the transfer of the English equivalents of micro-discursive means from the participants' L1 (Turkish) to the participants' academic writing in English. In a similar vein to Babanoğlu (2014), Ziyagham \& Simin (2018) argue that the occurrence of informal DMs in the corpus of academic essays written by Persian L1 EFL students is related to the transfer of the English equivalents of the informal DMs from Persian, the participants' L1, to the academic essays in English. Analogously to Babanoğlu (2014), Ziyagham \& Simin (2018) discuss register confusion in terms of the use of informal DMs in academic writing in the corpus of EFL essays in their study. Notably, Ziyagham \& Simin (2018) attribute the insertion of the informal English DMs in a formal academic text to the current 
prevalence of the communicative method in EFL teaching and learning, which is characterised by a notable lack of instructional attention to the formal register of the English language.

1.2. An outline of previous studies associated with peer review writing in EFL contexts

Whilst there is a substantial line of prior research that addresses the problem of peer review writing in a variety of contexts (Mulligan, Hall \& Raphael 2013; Paltridge 2017), there are a number of recent studies on peer review writing in EFL that are conducted from the vantage point of applied linguistics (Vorobel \& Kim 2014; McDonough, De Vleeschauwer \& Crawford 2018; Yallop \& Leijen 2018; Zhao 2018; de Brusa \& Harutyunyan 2019; Kim 2019; Kwon \& Kim 2019). There appear several themes that are related to various aspects of peer review writing in EFL contexts, for instance, in i) peer review writing by advanced EFL students (Yallop \& Leijen 2018); ii) oral discussion of peer review writing (Vorobel \& Kim 2014); iii) the pre-writing of peer review (McDonough, De Vleeschauwer \& Crawford 2018); iv) cultural and socio-cultural contexts of peer review writing (Zhao 2018; de Brusa \& Harutyunyan 2019); and v) identityrelated contexts of peer review writing (Kim 2019; Kwon \& Kim 2019).

The research theme of peer review writing by advanced EFL students at the doctoral level is examined by Yallop \& Leijen (2018). They investigate the effectiveness of written peer feedback comments provided by Estonian L1 EFL writers at the advanced level of language proficiency. The findings in Yallop \& Leijen (2018) are suggestive of the facilitative effect of the cover letter, which is provided by the writer with a piece of academic writing that is submitted for peer review. According to Yallop \& Leijen (2018), such a combination generates more effective revision comments than one without the cover letter. In addition, Yallop \& Leijen (2018) have discovered that peer review comments "that contain hedging and/or softening devices as being more effective than feedback comments presented with author or impartial certainty" (Yallop \& Leijen 2018: 269).

The topic of oral discussion within the peer review dyad is explored by Vorobel \& Kim (2014), who posit that peer review involves a constant appropriation of the author and reviewer roles. Vorobel \& Kim (2014) argue that the dyad in a peer review group construes itself as both author and reviewer. According to Vorobel \& Kim (2014), such a dual role enables the dyad to examine each other's writing from both the reviewer's and authors' standpoints. Vorobel \& Kim (2014) suggest that the duality of peer review interaction is facilitative of the peer review dyad's awareness of "the audience for their writing and to evaluate the organization of their ideas and the clarity of their expression" (Vorobel \& Kim 2014: 718). 
The research theme of collaborative pre-writing in peer review is addressed in a recent study conducted by McDonough, De Vleeschauwer \& Crawford (2018). In the study, the corpus of collaboratively pre-written texts by Thai L1 EFL students is further contrasted with collaborative text writing. The results of the investigation by McDonough, De Vleeschauwer \& Crawford (2018) indicate that collaborative texts appear to be more accurate than collaborative pre-writing, whereas collaborative pre-writing and non-collaborative texts are characterised by a substantially higher syntactic complexity in terms of the use of subordinate clauses.

The research topic of the impact of socio-cultural contexts upon peer review writing in EFL is present in the publications by Zhao (2018) and de Brusa \& Harutyunyan (2019). In particular, de Brusa \& Harutyunyan (2019) analyse peer review in writing as a learning tool from the vantage point of Vygotsky's sociocultural theory. De Brusa \& Harutyunyan (2019) have established that peer review has a positive impact on academic writing, especially as far as the communicative competence is concerned. Amongst other findings, de Brusa \& Harutyunyan (2019) note that the students in their peer reviews appear to prioritise content over style conventions associated with academic writing. Similarly to de Brusa \& Harutyunyan (2019), Zhao (2018) aims at elucidating the process of peer review in EFL writing through the lenses of the socio-cultural approach. Zhao's (2018) study involves 13 dyads of Mandarin L1 EFL students, who are requested to write peer reviews of several text genres after having receiving specialised training. The results in the study by Zhao (2018) are indicative of distinct interaction patterns of peer review writing and the associated variables, such as interactive peer interaction within the dyad.

The research theme of identity-related contexts in peer review writing is present in the recent publications by Kim (2019) and Kwon \& Kim (2019). Specifically, Kim (2019) focuses upon the process and the end result of peer review writing. Kim (2019) seeks to explore Japanese L1 EFL learners' perceptions of face-to-face versus anonymous peer review. Kim (2019) argues that whereas the prior literature is suggestive of difficulties on the part of Asian EFL learners with providing negative feedback due to cultural considerations, the results in Kim's (2019) study do not support the aforementioned view. In particular, the students in the study conducted by Kim (2019) perform equally well both in face-to-face and in anonymous modes of peer review writing. In line with Kim (2019), Kwon \& Kim (2019) explore how Korean L1 EFL students construe their identity in peer review writing process. The findings in Kwon \& Kim (2019) point to several types of writer's identity in the process of peer review writing, e.g., face negotiator, evaluator, junior and senior, facilitator, audience, and opinion-holder. Whilst initially the participants in the study by Kwon \& Kim (2019) appear to conform to the face-saving identity, they further negotiate their identities as a face negotiator and a facilitator. 
As evident from the abovementioned studies, there is a burgeoning line of research which is associated with various aspects of peer review writing by EFL students. However, there are insufficient studies that address the use of DMs in peer review writing by future EFL teachers. Further in the article, I will present and discuss an empirical investigation that aims at elucidating this issue.

\section{The present study, its hypothesis and specific research aims}

The present study is contextualised within the course in English didactics offered at a regional university in Norway to future EFL teachers. The aim of the course is to provide an overview of EFL didactics in relation to the teaching and learning of English in Norway. The course follows the course book English Teaching Strategies written by Drew \& Sørheim (2016). The course involves a take-home exam that consists of two academic essays on a range of topics in EFL didactics. These academic essays are supposed to be written during the whole semester and are expected to be submitted for evaluation at the end of the semester on the examination platform Wiseflow.

It should be clarified that the students have two academic essays to write, i.e., the first round of essays (henceforth E1) and the second round of essays (henceforth E2). Prior to the submission of E1 and E2 on Wiseflow, the students are instructed to form dyads in order to provide written feedback on each other's essays. In other words, each round of essays is peer reviewed by the participants so that each individual E1 gets its own peer review (henceforth R1), and each individual E2 receives its respective peer review (henceforth $\mathrm{R} 2$ ). It should be noted that whereas E1 and E2 are graded and the participants receive grades for them which are equal to the grades for the entire course in EFL didactics, the R1 and R2 are not grade bearing. In the course structure, both R1 and R2 are regarded as an "internal" measure that is meant to facilitate the quality of the essays. Both R1 and R2 could be argued to be less controlled in contrast to the participants' E1 and E2, since R1 and R2 are carried out only within the dyad of participants without any direct involvement and written feedback provided by the course teacher. To reiterate, both R1 and R2 are submitted on the university-internal study platform Canvas in contrast to E1 and E2 that are submitted on Wiseflow to be graded.

The study presented in the article seeks to provide a quantitative account of DMs that the participants employ in their peer review writing. Given the scarcity of previous research publications associated with the use of DMs in peer reviews written by EFL student writers, there are two hypotheses in this study. Hypothesis 1 is based upon the findings that are reported in the studies conducted by Šimčikaite (2012), Povolná (2013), and Babanoğlu (2014), who indicate that the use of DMs in academic writing by EFL student writers may involve DMs that 
are associated with the informal register of the English language (e.g., kind of, like, etc.). Using these findings as a point of departure, Hypothesis 1 in the present study factors in the informal milieu in which the peer reviews are written. It could be argued that the participants' peer review writing could be informal due to the following variables: i) the participants receive no grades for their peer reviews; ii) the participants get no feedback from the course teacher as far as their peer reviews are concerned; and iii) the participants experience no direct pressure on the part of the course teacher, who is the author of the present article, to write their peer reviews in academic English, even though the choice of the register of academic English is suggested. Arguably, these variables would facilitate the participants' choice of the informal DMs in their peer review writing. In line with this assumption, Hypothesis 1 is formulated as follows:

\begin{abstract}
Hypothesis 1. Given that the participants' peer reviews are not grade bearing and are written by the participants for the dyad-internal use without any form of supervision on the part of the course teacher, it is assumed in the present study that DMs in the participants' peer reviews would pertain to the informal register of the English language.
\end{abstract}

In contrast to Hypothesis 1, however, another hypothesis (i.e., Hypothesis 2) is considered possible in this study. Specifically, Hypothesis 2 is based upon the findings reported by Kapranov (2017), who suggests that future EFL teachers exhibit awareness of the formal requirements and genre conventions of academic writing in English. Subsequently, future EFL teachers' genre awareness is concomitant with the use of the formal register of the English language (Kapranov 2017). In addition, Hypothesis 2 takes into account the following variables: i) the course requirements to write the essays in the academic register of the English language; ii) the course teacher's feedback on the content and form of the essays (i.e., E1 and E2); and iii) the course teacher's suggestion to write informative and objective peer reviews, preferably in the formal register of English. However, as previously mentioned, the latter variable is not controlled in the study. It means that peer review writing could, potentially, be executed in academic English, since it is up to an individual participant to follow up on that suggestion. Taking into account these variables as well as the findings in the study by Kapranov (2017), Hypothesis 2 is stated as follows:

Hypothesis 2. Assuming that the participants have been explicitly instructed to write their academic essays in the formal register of the English language in addition to being suggested to write their peer reviews in academic English, it is hypothesised that DMs in the participants' peer reviews would pertain to the formal and/or neutral registers of the English language. 
Based upon these two hypotheses, the following specific research aims are formulated:

i) to establish the frequencies of DMs in the participants' peer reviews;

ii) to establish the frequencies of DMs in the participants' academic essays;

iii) to juxtapose the frequencies of DMs in the corpus of peer reviews and academic essays;

iv) to establish the frequencies of DMs that are associated with the formal and neutral registers of the English language in the corpus of the peer reviews and academic essays;

iv) to establish the frequencies of DMs that are associated with the informal register of English in the corpus of the peer reviews and academic essays.

\subsection{Participants}

In total, 12 participants ( $\mathrm{M}$ age $=22.4$ y.o., standard deviation $=3.0)$ took part in the study. The participants were enrolled in a teacher training programme at a regional university in Norway. All participants were speakers of Norwegian as their L1. As far as the participants' socio-linguistic background was concerned, the following should be noted. In Norway, there are two official languages, Norwegian and Saami, whereas Kven and Romani are considered regional and minority languages, respectively. There were no participants in this study who reported being associated with the socio-linguistic backgrounds other than Norwegian.

In terms of the participants' proficiency in the English language, the participants were assumed to be on the intermediate B1/B2 level of proficiency in English according to the Common European Framework of Reference for Languages: Teaching, Learning and Assessment, or CEFR (Council of Europe 2011). This assumption was based upon the participants' secondary school leaving certificates that indicated that their English proficiency was on the B1/B2 levels. In this regard, it should be clarified that in Norway there are no university entrance exams as far as teacher training programmes are concerned and the prospective students are admitted to university programmes based upon the marks from their school-leaving exams. Norwegian secondary school leavers are expected to pass their schoolleaving exam in English at the B1/B2 levels of proficiency.

The participants were requested to sign consent forms that allowed the author of the article to collect and process their written data for scientific purposes. To ensure confidentiality, the participants' real names were coded (the codes are $\mathrm{P}$ as in participant and the number, e.g., P 1, P 2, P 3, .. P 12). 


\subsection{Procedure, corpus and method}

The study involved the following procedure. The participants $(\mathrm{N}=12)$ were asked to form dyads $(\mathrm{N}=6)$ for the peer review writing. The dyads were instructed to provide written reviews of each other's academic essays in EFL didactics, focusing upon the form, content, and the use of academic English. The participants were instructed to write their peer reviews in a professional manner in order to provide constructive and objective criticism of their dyad partners' essays. It was suggested to the participants that they use academic English. Importantly, the participants were reminded that their essays in EFL didactics (e.g., E1 and E2) should be written in academic English.

The step-by-step procedure in the present study was as follows. First, the participants were asked to write their E1, upload them onto the study platform Canvas, and then in their respective dyads provide written peer reviews of E1 and submit them on Canvas within two weeks from E1 submission. Second, the participants were requested to write E2, upload them onto Canvas, and write the peer reviews of E2 in the respective dyad. Third, the participants were reminded to upload their final reviewed essays (both E1 and E2) onto the examination platform Wiseflow. The participants' essays and peer reviews formed two corpora in the present study, namely the corpus of peer reviews and the corpus of academic essays in their final form, i.e., those essays that the participants submitted on Wiseflow. The descriptive statistics of these two corpora were summarised in Table 1 below.

Table 1. The descriptive statistics of the corpus of peer reviews (R1 and R2) and academic essays (E1 and E2)

\begin{tabular}{c|l|c|c|c|c}
\hline $\mathrm{N}$ & Measure & $\mathrm{E} 1$ & $\mathrm{E} 2$ & $\mathrm{R} 1$ & $\mathrm{R} 2$ \\
\hline 1 & $\begin{array}{l}\text { Total number of } \\
\text { words }\end{array}$ & 14275 & 13504 & 2564 & 2100 \\
\hline 2 & Mean words & 1189 & 1125 & 128 & 175 \\
\hline 3 & Standard deviation & 198.3 & 216.1 & 154.8 & 113.4 \\
\hline 4 & Minimum & 876 & 758 & 84 & 83 \\
\hline 5 & Maximum & 1709 & 1525 & 561 & 404 \\
\hline
\end{tabular}

Methodologically, the present study was informed by the definition of DMs proposed by Fraser (1999). In accordance with Fraser (1999), DMs were regarded as lexical items that imposed a discourse-related relationship between two adjacent discursive segments, typically represented by two sentences, Sentence 1 and Sentence 2 (Fraser 1999: 938). In the present article, however, the 
aforementioned view of DMs was extended to include DMs that occurred in sentence-initial positions in a Sentence 1 - Sentence 2 combination, and in clause-initial positions in a Clause 1 - Clause 2 combination. Such an approach to DMs in the present study could be illustrated by the following examples:

a) If you learn what it is that goes into the making of a memorable sentence what skills of coordination, subordination, allusion, compression, parallelism, alliteration (all terms to be explained later) are in play - you will also be learning how to take the appreciative measure of such sentences. And conversely, if you can add to your admiration of a sentence an analytical awareness of what caused you to admire it, you will be that much farther down the road of being able to produce one (somewhat) like it. (Fish 2011: 15)

b) Chronic stress impairs rat spatial memory on the Y maze, and this effect is blocked by tianeptine treatment. (Conrad et al. 1996: 1322)

c) The semiconductor industry has seen a remarkable miniaturization trend, driven by many scientific and technological innovations. (Joachim, Gimzewski \& Aviram 2000: 541).

According to the definition of DMs proposed by Fraser (1999) and modified in this study, and in (a) and (b) was treated as a DM, i.e., a discursive element that was employed to express discourse-related relationships between the discourse segments (Fraser 1999), whilst and in (c) was regarded as a conjunction in the noun phrase "scientific and technological innovations", which was not concomitant with a particular discursive relationship between clauses and sentences. Specifically, the DM and was deemed to be involved in signalling discourse-related relationships between the segments in i) the Sentence 1 Sentence 2 combination in (a), and ii) the Clause 1 - Clause 2 combination in (b). However, and in (c) was not analysed as a DM, whereas and both in (a) and (b) was regarded as a DM in the present investigation. Following this view of DMs, the possible candidates for DMs in the present research were based upon the list of DMs that was found in Fraser (1999) and further specified in the studies conducted by Povolná (2013) and Fraser (2015), respectively. In line with the aforementioned studies, the list of potential DMs could be comprised of, for instance, above all, accordingly, all in all result, also, alternatively, and, as a conclusion, as a consequence, but, consequently, conversely, despite that, given that, hence, however, if, in other words, in fact, in contrast, instead, moreover, nevertheless, on the contrary, on the other hand, rather, so, still, then, therefore, thus, and yet (Povolná 2013; Fraser 2015).

As far as the methodology of the data analysis was concerned, it involved two stages, Stage 1 and Stage 2, respectively. At Stage 1, the corpora in this study were analysed using the WordSmith Tools (Scott 2008) software program in 
order to establish the frequency of DMs per participant per task. Thereafter, the data analysis was executed using WordSmith's WordList function that generated word lists based upon frequency that were alphabetically ordered. WordSmith allowed to process individual texts (i.e., files), as well as the whole corpus (see a detailed description of the program and its functions in Scott 2001). The output files with the word frequencies generated by WordSmith were manually checked by the author of this article against the original texts in order to verify whether or not the DMs conformed to the definition of DMs used in the study. Once the frequency of the DMs was established and manually verified, the respective means and standard deviations of DMs per task per group were calculated by the author using the software program Statistical Package for Social Sciences (SPSS), version 24.0 (IBM 2016). It should be clarified that the means and standard deviations were based upon the so-called 'raw' data, i.e., they were based upon the statistical values that were not normalised.

Stage 2 of the data analysis in this study followed the research methodology described by Povolná (2013). In line with Povolná (2013), the data in the present study were normalised for the frequency of the occurrence of DMs per 1000 words per group of participants. In this regard, it should be observed that the frequency of DMs per 1000 words was deemed to be a standard measure in normalising the data (Aijmer 2002; Wolk, Götz \& Jäschke 2021). Given that the corpora in this study differed in the total number of words (see Table 1), the frequencies of DMs in the corpora were calculated by the program WordSmith (Scott 2008) based upon the 1000 word cut-off in order to enable cross-comparison of DMs in all tasks, i.e., E1 $(\mathrm{N}=12)$, $\mathrm{E} 2(\mathrm{~N}=12)$, as well as all $\mathrm{R} 1(\mathrm{~N}=12)$ and $\mathrm{R} 2(\mathrm{~N}=12)$. The individual texts were merged into four respective files and analysed in WordSmith so that there were four files in total for the quantitative analysis at stage 2 (in other words, file \#1 contains all E1, file \#2 contains all R1, file \#3 has all E2, and file \#4 has all R2). Following Povolná (2013: 136), the results of the normalised data analysis were given as percentages in this article.

\subsection{Results}

The quantitative analysis of the corpora yielded the results that were given in Tables 2-3 below. In Table 2, the results were presented in the form of means (M) and standard deviations (SD) of the non-normalised data.

Table 2. Means (M) and standard deviations (SD) of DMs in non-normalised data in all tasks

\begin{tabular}{c|l|c|c|c|c}
\hline $\mathrm{N}$ & DMs & E1 & E2 & R1 & R2 \\
\hline 1 & Additionally & - & M 1; SD 0 & - & M 1; SD 0 \\
\hline 2 & Also & M 1.3; SD 1 & M 1.5; SD 1 & M 2; SD 1 & M 1.3; SD 1.1 \\
\hline
\end{tabular}




\begin{tabular}{|c|c|c|c|c|c|}
\hline 3 & Although & M 1; SD 0 & M 1; SD 0 & - & - \\
\hline 4 & And & M 4.3; SD 1.5 & M 4.1; SD 1.3 & M 2.2; SD 0.8 & M 2.8; SD 1.5 \\
\hline 5 & As & M 1.5; SD 1 & M 1.5; SD 1 & M 1.1; SD 0.5 & M 1.6; SD 1 \\
\hline 6 & Because & - & - & M 1; SD 0 & - \\
\hline 7 & Besides & - & M 1; SD 0 & - & - \\
\hline 8 & But & M 1.9; SD 1.5 & M 1.7; SD 1 & M 1.4; SD 0.5 & M 1.8; SD 1.3 \\
\hline 9 & Clearly & M 1; SD 0 & M 1.4; SD 1 & - & M 1; SD 0 \\
\hline 10 & Especially & M 1; SD 0 & - & - & M 1; SD 0 \\
\hline 11 & Eventually & M 1; SD 0 & - & - & - \\
\hline 12 & Finally & M 1; SD 0 & M 1; SD 0 & - & - \\
\hline 13 & Firstly & - & M 1; SD 0 & - & M 1; SD 0 \\
\hline 14 & Further & M 1; SD 0 & M 1; SD 0 & M 1; SD 0 & M 1; SD 0 \\
\hline 15 & Furthermore & M 1; SD 0 & M 1; SD 0 & M 1; SD 0 & M 1; SD 0 \\
\hline 16 & If & M 1.5; SD 1 & M $1.7 ;$ SD 0.9 & M 1; SD 0 & M 1; SD 0 \\
\hline 17 & However & M 2.1; SD 1 & M 1.9; SD 1.2 & M 1; SD 0 & M 1; SD 0 \\
\hline 18 & Just & M 1.7; SD 1 & M 1; SD 0 & M 1; SD 0 & M 1; SD 0 \\
\hline 19 & Lastly & M 1; SD 0 & M 1; SD 0 & - & - \\
\hline 20 & Mainly & - & M 1; SD 0 & - & M 1; SD 0 \\
\hline 21 & Moreover & M 1; SD 0 & - & - & - \\
\hline 22 & Normally & M 1; SD 0 & - & - & - \\
\hline 23 & Obviously & - & M 1; SD 0 & - & - \\
\hline 24 & Occasionally & - & M 1; SD 0 & - & - \\
\hline 25 & Often & M 1.3; SD 0.5 & M 1; SD 0 & - & - \\
\hline 26 & Or & M 1.2; SD 0.4 & M 1.1; SD 0.5 & M 1; SD 0 & M 1; SD 0 \\
\hline 27 & Perhaps & - & M 1; SD 0 & M 2; SD 0 & M 1; SD 0 \\
\hline 28 & Previously & M 1; SD 0 & M 1; SD 0 & - & - \\
\hline 29 & Probably & - & M 1; SD 0 & M 1.5; SD 1 & - \\
\hline 30 & Rather & M 1; SD 0 & M 1; SD 0 & M 1.3; SD 0.5 & - \\
\hline 31 & Secondly & - & M 1; SD 0 & M 1; SD 0 & - \\
\hline 32 & So & M 1.9; SD 0.8 & M 1.3; SD 0.5 & M 2; SD 1 & M 2; SD 1.5 \\
\hline 33 & Specifically & - & M 1; SD 0 & - & M 1; SD 0 \\
\hline 34 & Still & - & M 1.2; SD 0.3 & - & M 1; SD 0 \\
\hline 35 & Subsequently & - & M 1; SD 0 & M 2; SD 0 & - \\
\hline 36 & Such & M 2.2; SD 1.5 & - & - & - \\
\hline 37 & Surely & M 1; SD 0 & - & - & - \\
\hline 38 & Then & M 1.4; SD 1 & M 1; SD 0 & M 1; SD 0 & M 1; SD 0 \\
\hline 39 & Therefore & M 1.5; SD 0.5 & M 1.1; SD 0.4 & - & - \\
\hline 40 & Thus & - & M 1.3; SD 1 & - & - \\
\hline 41 & Typically & - & M 1; SD 0 & - & - \\
\hline
\end{tabular}




\begin{tabular}{c|l|c|c|c|c}
\hline 42 & Undoubtedly & M 1; SD 0 & - & - & - \\
\hline 43 & Unlike & - & M 1; SD 0 & - & - \\
\hline 44 & Usually & - & M 1; SD 0 & - & M 1; SD 0 \\
\hline 45 & Whenever & M 1; SD 0 & M 1; SD 0 & - & - \\
\hline 46 & While & M 1.7; SD 1.2 & M 1; SD 0 & - & - \\
\hline 47 & Yet & - & M 1; SD 0 & - & - \\
\hline
\end{tabular}

Whereas Table 2 summarised the results of the non-normalised data, Table 3 illustrated the results of the frequency count of the DM in the corpora of R1 and R2 and E1 and E2, respectively normalised per 1000 words per group. The normalised frequency of DMs in Table 3 was given in all tasks (E1, E2, R1, R2). The DMs in Table 3 were presented in alphabetical order.

Table 3. The frequency of DMs normalised per 1000 words

\begin{tabular}{l|l|c|c|c|c}
\hline $\mathrm{N}$ & DMs & $\mathrm{E} 1$ & $\mathrm{E} 2$ & $\mathrm{R} 1$ & $\mathrm{R} 2$ \\
\hline 1 & Additionally & - & $0.02 \%$ & - & $0.01 \%$ \\
\hline 2 & Also & $0.3 \%$ & $0.4 \%$ & $0.6 \%$ & $0.3 \%$ \\
\hline 3 & Although & $0.01 \%$ & $0.01 \%$ & - & - \\
\hline 4 & And & $3.1 \%$ & $3 \%$ & $2.3 \%$ & $2.7 \%$ \\
\hline 5 & As & $1.1 \%$ & $1.2 \%$ & $0.7 \%$ & $1.3 \%$ \\
\hline 6 & Because & - & - & $0.04 \%$ & - \\
\hline 7 & Besides & - & $0.01 \%$ & - & - \\
\hline 8 & But & $0.3 \%$ & $0.2 \%$ & $0.1 \%$ & $0.3 \%$ \\
\hline 9 & Clearly & $0.01 \%$ & $0.02 \%$ & - & $0.01 \%$ \\
\hline 10 & Especially & $0.01 \%$ & - & - & $0.01 \%$ \\
\hline 11 & Eventually & $0.01 \%$ & - & - & - \\
\hline 12 & Finally & $0.01 \%$ & $0.02 \%$ & - & - \\
\hline 13 & Firstly & - & $0.02 \%$ & - & $0.01 \%$ \\
\hline 14 & Further & $0.01 \%$ & $0.05 \%$ & $0.08 \%$ & $0.01 \%$ \\
\hline 15 & Furthermore & $0.01 \%$ & $0.01 \%$ & $0.01 \%$ & $0.01 \%$ \\
\hline 16 & If & $0.1 \%$ & $0.2 \%$ & $0.04 \%$ & $0.03 \%$ \\
\hline 17 & However & $0.2 \%$ & $0.2 \%$ & $0.04 \%$ & $0.04 \%$ \\
\hline 18 & Just & $0.1 \%$ & $0.08 \%$ & $0.03 \%$ & $0.01 \%$ \\
\hline 19 & Lastly & $0.01 \%$ & $0.01 \%$ & - & - \\
\hline 20 & Mainly & - & $0.01 \%$ & - & $0.01 \%$ \\
\hline 21 & Moreover & $0.01 \%$ & - & - & - \\
\hline 22 & Normally & $0.01 \%$ & - & - & - \\
\hline 23 & Obviously & - & $0.01 \%$ & - & - \\
\hline 24 & Occasionally & $0.01 \%$ & - & - \\
\hline & & & & & \\
\hline & & - & - & - \\
\hline
\end{tabular}




\begin{tabular}{l|l|c|c|c|c}
\hline 25 & Often & $0.2 \%$ & $0.07 \%$ & - & - \\
\hline 26 & Or & $0.5 \%$ & $0.5 \%$ & $0.01 \%$ & $0.04 \%$ \\
\hline 27 & Perhaps & - & $0.01 \%$ & $0.08 \%$ & $0.01 \%$ \\
\hline 28 & Previously & $0.01 \%$ & $0.01 \%$ & - & - \\
\hline 29 & Probably & - & $0.01 \%$ & $0.1 \%$ & - \\
\hline 30 & Rather & $0.01 \%$ & $0.04 \%$ & $0.08 \%$ & - \\
\hline 31 & Secondly & - & $0.02 \%$ & $0.04 \%$ & - \\
\hline 32 & So & $0.2 \%$ & $0.1 \%$ & $0.4 \%$ & $0.3 \%$ \\
\hline 33 & Specifically & - & $0.01 \%$ & - & $0.01 \%$ \\
\hline 34 & Still & - & $0.04 \%$ & - & $0.01 \%$ \\
\hline 35 & Subsequently & - & $0.01 \%$ & $0.04 \%$ & - \\
\hline 36 & Such & $0.2 \%$ & - & - & - \\
\hline 37 & Surely & $0.01 \%$ & - & - & - \\
\hline 38 & Then & $0.1 \%$ & $0.03 \%$ & $0.02 \%$ & $0.03 \%$ \\
\hline 39 & Therefore & $0.1 \%$ & $0.06 \%$ & - & - \\
\hline 40 & Thus & - & $0.06 \%$ & - & - \\
\hline 41 & Typically & - & $0.01 \%$ & - & - \\
\hline 42 & Undoubtedly & $0.01 \%$ & - & - & - \\
\hline 43 & Unlike & - & $0.01 \%$ & - & - \\
\hline 44 & Usually & - & $0.01 \%$ & - & $0.01 \%$ \\
\hline 45 & Whenever & $0.01 \%$ & $0.02 \%$ & - & - \\
\hline 46 & While & - & $0.01 \%$ & - & - \\
\hline 47 & Yet & & & - \\
\hline
\end{tabular}

\subsection{Discussion}

Following the aims of the study, the frequencies of DMs in R1 and R2 are summarised in Table 3 alongside the analogous frequencies of DMs in E1 and E2, respectively. Further in this section of the article, I will discuss the findings through the lenses of i) the juxtaposition of the DMs in the peer reviews (i.e., R1 and R2) and academic essays (i.e., E1 and E2) in subsection 2.4.1, and ii) the formal versus informal use of the DMs in the corpus of the peer reviews in subsection 2.4.2.

\subsubsection{The juxtaposition of the DMs in the peer reviews and academic essays}

It is evident from Tables 2 and 3 that the distribution of the DMs varies in the present corpora. Specifically, there are groups of DMs that are present in i) the corpora of academic essays and peer reviews (i.e., E1, E2, R1 and R2), ii) exclusively in the corpus of academic essays (i.e., E1 and E2), and iii) only in E2 
and R2. As seen in Tables 2 and 3, there is a group of DMs that have been identified both in the corpus of academic essays and the corpus of peer reviews, e.g., also, and, as, but, further, furthermore, if, however, just, or, so, and then. Judging from the data analysis, there are no statistically significant differences in the distribution of the aforementioned DMs in the corpora. Specifically, a oneway analysis of variance (ANOVA) of the raw data was performed to look for statistically significant differences in the distribution of DMs between essays and reviews. The analysis did not yield statistically significant results $[\mathrm{F}(3,92)=$ $2.381, \mathrm{p}=.075]$.

Whilst there are no statistically significant differences in the distribution of the DMs that occur both in the corpus of academic essays and the corpus of peer reviews, it is seen in Table 3 that the occurrence of the DMs further and furthermore is relatively low in E1, E2, R1, and R2 in terms of the normalised values in contrast to the occurrence of the DMs also, and, as, but and so that are comparatively more frequent in the corpora. This finding is exemplified by Figure 1 below.

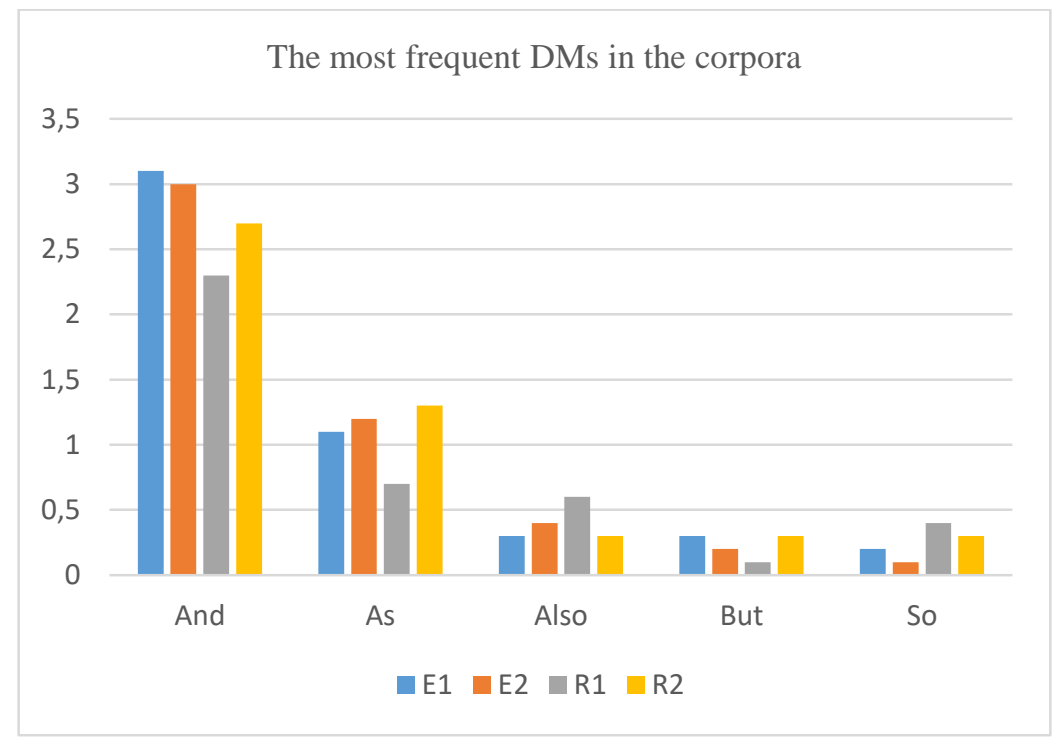

Figure 1. The most frequent DMs in the corpora

It follows from Figure 1 and Table 3 that and is the most frequent DM in the corpora. In particular, its frequency is the highest in the corpus of E1 and E2, where the DM and is similarly distributed. The occurrence of the DM and is emblematised by the following excerpt, which is taken from the participant's R1, e.g. 
1) Some of your clause structures are not written in a proper academic language. They sound more informal. And some of your clauses have a "Norwegian" feel instead of English. I have not checked for all spelling errors but point out some that are rather severe in my opinion. (Participant P 2, female).

A relatively high frequency of the DM and in the present corpora is in line with the studies conducted by Chen (2006), Šimčikaitè (2012), Povolná (2013), Unaldi (2013), and Bax, Nakatsuhara \& Waller (2019), who indicate that EFL student writers exhibit a tendency to use the DM and more frequently in comparison with other DMs. In addition to the DM and, other most frequent DMs in the corpus of peer reviews and in the corpus of academic essays are also, as, but, and so. This finding is in unison withe the prior literature (Chen 2006; Povolná 2013; Unaldi 2013; Gil 2018; Bax, Nakatsuhara \& Waller 2019) that reports an extensive use of these DMs in academic writing by undergraduate EFL students.

Presumably, a possible explanation of the relatively high frequency of the DMs also, and, as, but and so in the present study could be provided by a semiautomatic and/or subconscious transfer of DMs from Norwegian, the participants' L1, to their writing in English.

This assumption is concomitant with the findings in the studies conducted by Babanoğlu (2014), and Ziyagham \& Simin (2018), who report that the EFL student writers transfer English equivalents of the DMs found in their respective L1 to academic writing in English. Arguably, this could be the case in the present study, given that the English and Norwegian languages are typologically close (Johansen 2020). Moreover, English and Norwegian share a substantial number of similar lexical and grammatical features (Westergaard et al. 2017). In addition to the typological closeness, the DMs also, and, as, but and so and their Norwegian equivalents frequently occur in a variety of discourse-communicative settings both in the English and Norwegian languages (Johansen 2020). This could be another variable that accounts for the relatively high frequency of also, and, as, but and so in the present study. In this regard, it should be mentioned that the Norwegian analogues of the English DMs also (Norwegian også), and (Norwegian og), but (Norwegian men), as (Norwegian som) and so (Norwegian $s a)$ are reported to be frequent in various registers of the Norwegian language (Johansen 2020). Consequently, it could be possible to assume that the frequent occurrence of the aforementioned English DMs in the corpora is facilitated by the participants' subconscious transfer of the Norwegian analogues of these DMs to their writing in English. Obviously, this assumption cannot be verified in the present study, since a separate investigation would be necessary with two parallel corpora of academic essays and their peer reviews in EFL and in Norwegian, 
respectively. Hopefully, such an investigation would offer new avenues of research on the use of DMs by EFL student writers.

In addition to the DMs that are present in the corpus of E1 and E2, as well as in the corpus of R1 and R2, the results of the data analysis summarised in Tables 2 and 3 point to the group of DMs that are found exclusively in E2 and R2. These DMs are additionally (0.02\% in E2; $0.01 \%$ in R2), firstly (0.02\% in E2; $0.01 \%$ in R2), mainly (0.01\% in E2; $0.01 \%$ in R2), specifically $(0.01 \%$ in E2; $0.01 \%$ in R2), still (0.04\% in E2; $0.01 \%$ in R2), and usually (0.01\% in E2; $0.01 \%$ in R2). Further, the distributions of these DMs in E2 and R2 are illustrated by Figure 2 , where the distributions have been plotted in the normalised values.

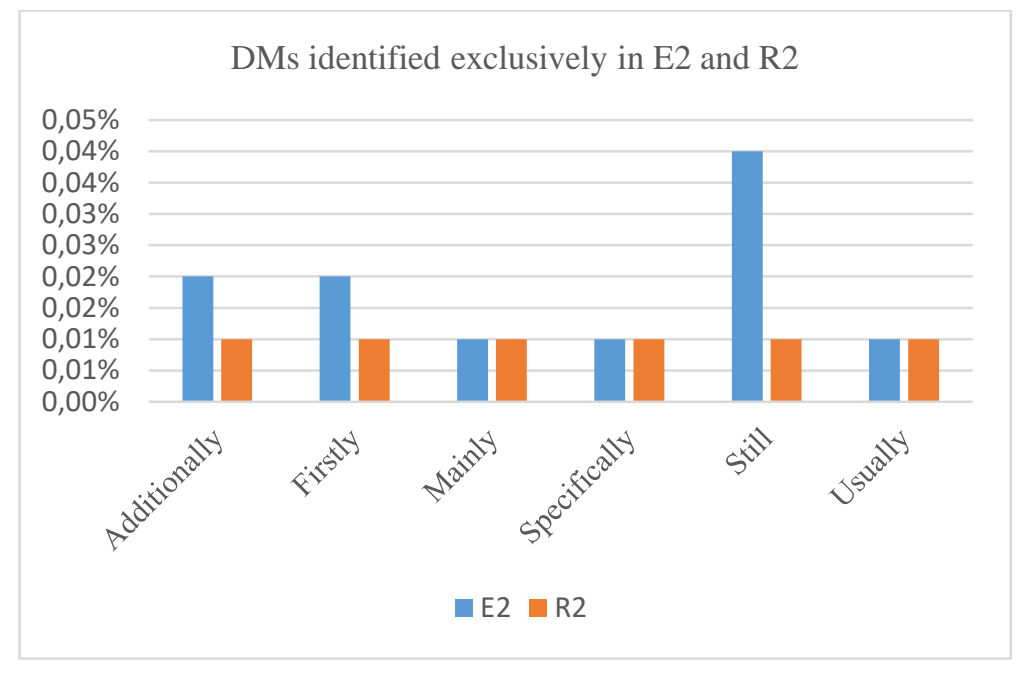

Figure 2. DMs identified exclusively in E2 and R2

It is seen in Figure 2 that the DMs additionally, firstly, mainly, specifically, still, and usually are equally distributed in $\mathrm{R} 2$ as far as the normalised data are concerned. It should also be emphasised that these DMs are not found in R1. They seem to have appeared only after the second round of essay writing (i.e., E2). Excerpt (2) below illustrates the use of some of these DMs by the participant, e.g.

2) This essay is very well written. [...] Additionally, your statements and opinions have research behind them. You discuss the benefits and challenges about utilizing content and language integrated teaching, still you do not mention other teaching methods that may be used in school when teaching English as a foreign language. (Participant P 8, female) 
Whereas the participant uses the DMs additionally and still in R2 (see excerpt 2), the participant does not employ these DMs in her E1 and R1. In a similar manner, the participants start using the DMs firstly, mainly, specifically, and usually in their peer reviews after the completion of E2 writing. It is possible to assume that the participants' collaborative work in dyads facilitates the borrowing of microdiscursive elements from the essays in the dyad. In other words, the participants could be said to converge on each other's micro-discursive means. This assumption is evocative of the argument proposed by Vorobel \& Kim (2014), who suggest that a typical peer review is associated with an on-going appropriation of the dual role of writer and reviewer. By means of engaging in peer review writing, the participants might borrow and/or exchange micro-discursive means inclusive of DMs, in addition to exchanging ideas as suggested by Vorobel \& Kim (2014). Arguably, the present finding validates the view of peer review writing as a form of interaction that provides EFL learners with an opportunity to exchange linguistic forms and apply these forms to the practical use in academic and peer review writing (Crawford, McDonough \& Brun-Mercer 2019).

At the same time, it is observed in the data that in contrast to the DMs that are found exclusively in E2 and R2, there is a group of DMs which is present only in $\mathrm{E} 1$ and absent in R1, R2 and E2. This group is represented by the DMs eventually $(0.01 \%)$, moreover $(0.01 \%)$, normally $(0.01 \%)$, such $(0.2 \%)$ surely $(0.01 \%)$, and undoubtedly $(0.01 \%)$. The frequency of these DMs is exemplified by Figure 3 below.

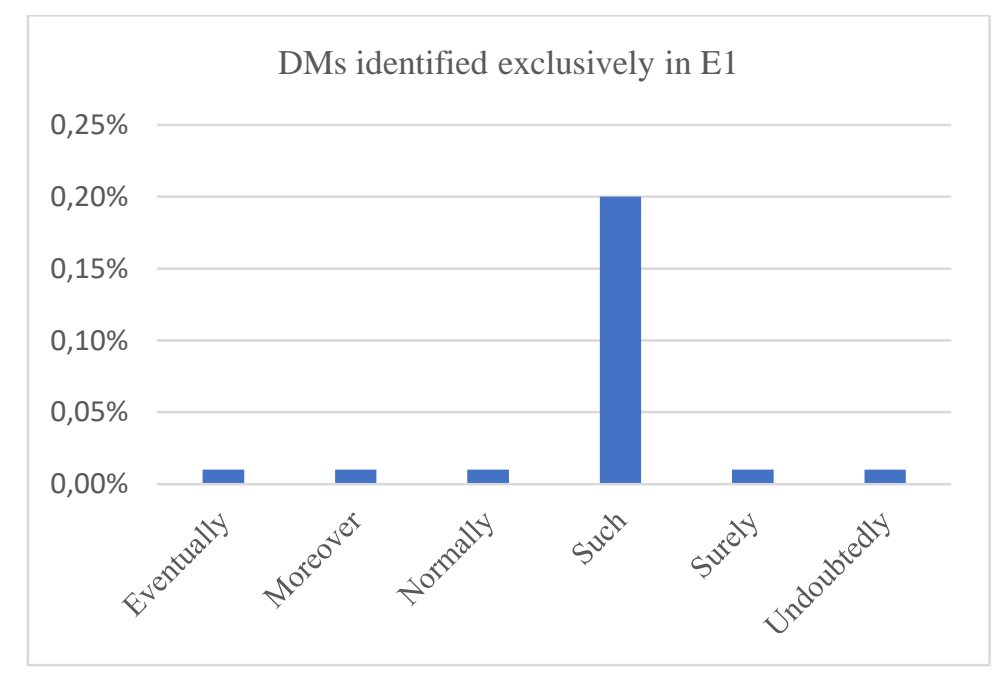

Figure 3. DMs identified exclusively in E1 
It is seen in Figure 3 that the participants tend to make an extensive use of the DM such in their E1. However, the use of the DMs such, as well as eventually, moreover, normally, surely, and undoubtedly disappears in E2, R1 and R2, respectively. Arguably, the use of these DMs is associated with a strong stance and a certain degree of assertiveness on the part of the writer (e.g., eventually, normally, surely, undoubtedly), as seen in the following quote, "Such a definition makes it impossible for a person who is illiterate to be fluent in his or her native language, and is not beneficial in this context" (Participant P 7, female). This quote demonstrates a strong stance on the part of the participant that is associated with the evaluative lexis (e.g., impossible, not beneficial). The participant's strong stance is introduced by the DM such that foregrounds the strategy to draw the readers' attention to the definition of speech fluency that the participant considers "not beneficial in this context" (Participant P 7). In contrast to E1, however, the participants resort to a less assertive style of writing in the second round of academic essays and the second round of peer reviews that results in the disappearance of the DMs such, eventually, moreover, normally, surely, and undoubtedly. The absence of these DMs in E2, R1, and R2 could be suggestive of the participants' strategy to mitigate a strong stance that they exhibit in E1.

Another noteworthy observation concerns the DMs that are present in E1 and $\mathrm{E} 2$, but are not found in the corpus of R1 and R2. These DMs are although (0.01\% in E1; $0.01 \%$ in E2), finally ( $0.01 \%$ in $\mathrm{E} 1 ; 0.02 \%$ in E2), lastly $(0.01 \%$ in $\mathrm{E} 1 ; 0.01 \%$ in $\mathrm{E} 2)$, often ( $0.2 \%$ in $\mathrm{E} 1 ; 0.07 \%$ in $\mathrm{E} 2)$, previously $(0.01 \%$ in $\mathrm{E} 1$; $0.01 \%$ in $\mathrm{E} 2)$, whenever $(0.01 \%$ in $\mathrm{E} 1 ; 0.02 \%$ in $\mathrm{E} 2)$, and while $(0.1 \%$ in $\mathrm{E} 1$; $0.01 \%$ in E2), as seen in Figure 4.

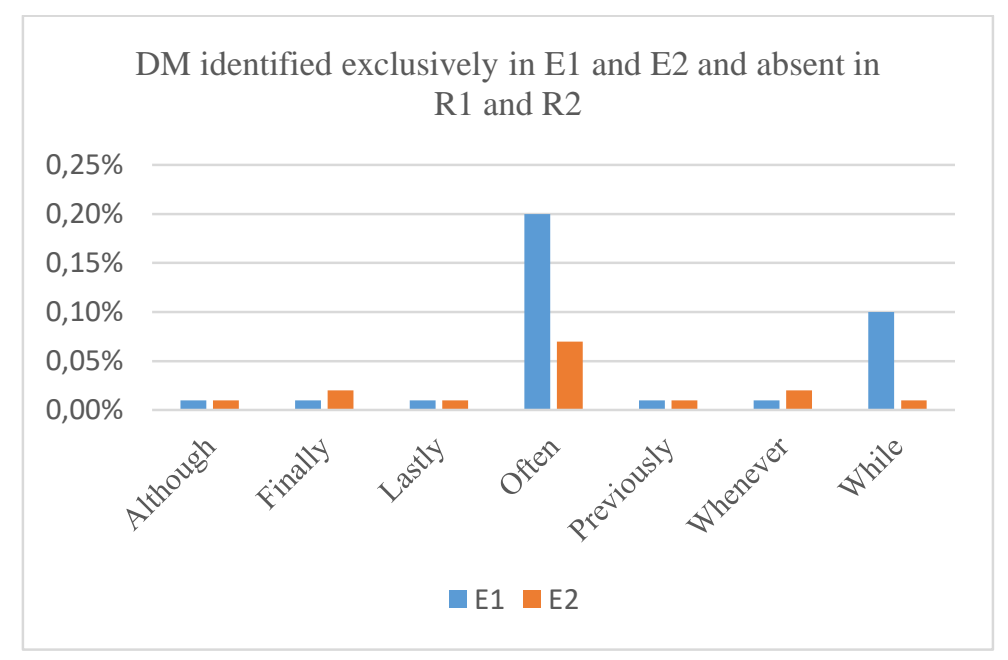

Figure 4. DM identified exclusively in E1 and E2 
Presumably, a possible explanation of the occurrence of the DMs finally, lastly, often, previously, whenever, and while in the corpus of E1 and E2 essays is associated with the temporal relations. It could be argued that these DMs are employed by the participants in an attempt to give their essays a temporal and structural scaffolding. The occurrence of such DMs as previously, finally, while, etc., appears logical in an academic essay that is characterised by a clear structure as well as a cohesive and logical manner of argumentation. In contrast to a wellstructured and cohesive academic essay, a typical peer review text involves a limited number of moves in the sense posited by Swales (1990). It should be specified that a move according to Swales is deemed to be a functional textual unit that is associated with an identifiable rhetorical purpose. In this regard, I agree with Connor \& Mauranen (1999), who indicate that moves in academic writing in English can vary in size and number. Whilst it is beyond the scope of the present article to provide an exhaustive analysis of moves in peer review writing, it is observed in the corpus of peer reviews that the participants employ a relatively limited number of moves there. Typically, a set of moves in the corpus of R1 and R2 in the present study involves Move 1 "Praise/Compliment" (i.e., the reviewers commence their peer review writing with a short description of the positive aspects of the reviewed essay) and Move 2 "Critical Feedback/Suggestions". The latter Move appears to involve constructive criticism and a series of suggestions that concern the form, content, logical ties, as well as the references section of the essays.

Following this line of reasoning, it seems logical to assume that the DMs which are involved in conveying temporal and structural relationships are less relevant in a much more succinct discursive space of the peer review writing, which is characterised by a limited number of moves (Swales 1990) and words, respectively. In terms of the latter, the descriptive statistics of the corpora summarised in Table 1 demonstrate that the total number of words in E1 is 14 275, whereas in R1 it is 2564 . Similarly, the total number of words in E2 is 13504 compared with the total number of words in R2, namely 2100 words in total. Presumably, a more compact text of the peer review facilitates the creation of a discursive space, where tempo-structural micro-discursive elements, such as the DMs finally, lastly, often, previously, whenever, and while are redundant.

2.3.2. The use of formal/neutral versus informal DMs in the corpus of peer reviews

As previously mentioned, one of the aims of the study is to examine the corpus of peer reviews in order to compare the frequencies of formal and neutral DMs on the one hand and informal DMs on the other. The comparison is related to the 
hypotheses in the study that involve the assumptions that the use of DMs in the participants' peer reviews would pertain to i) the informal register of English (i.e., Hypothesis 1), or, alternatively, ii) to the formal and neutral registers of the English language (i.e., Hypothesis 2). The prior literature (Šimčikaitė 2012; Babanoğlu 2014; Ziyagham \& Simin 2018) indicates that EFL student writers often resort to using the DMs that are associated with the informal register of the English language, such as oh, well, I mean, and like (see Babanoğlu (2014) for an exhaustive list of examples of informal DMs). Judging from the data summarised in Tables 2 and 3, there are no DMs that are associated with the informal register of English (see Šimčikaite (2012) and Babanoğlu (2014) for the potential candidates for informal DMs). Hence, Hypothesis 1 is to be rejected, whereas Hypothesis 2 is to be accepted. To reiterate, the corpus of the DMs in the present study seems to be comprised solely of the DMs that pertain to the formal and neutral registers of the English langauge. Following Hyland (2008), Šimčikaite (2012), and Povolná (2013), formal and neutral (or, in Šimčikaitè's (2012) terminology, "semi-formal") DMs are considered genre-appropriate microdiscursive means in academic writing in English.

The neutral DMs in the present corpus are illustrated by the DMs additionally ( $0.01 \%$ in $\mathrm{R} 2)$, also ( $0.6 \%$ in $\mathrm{R} 1 ; 0.3 \%$ in $\mathrm{R} 2)$, and $(2.3 \%$ in $\mathrm{R} 1 ; 2.7 \%$ in $\mathrm{R} 2)$, as ( $0.7 \%$ in $\mathrm{R} 1 ; 1.3 \%$ in $\mathrm{R} 2)$, because ( $0.04 \%$ in $\mathrm{R} 1)$, but $(0.1 \%$ in $\mathrm{R} 1 ; 0.3 \%$ in $\mathrm{R} 2)$, clearly $(0.01 \%$ in $\mathrm{R} 2)$, especially ( $0.01 \%$ in R2), firstly $(0.01 \%$ in $\mathrm{R} 2)$, if (0.04\% in R1; $0.03 \%$ in R2), however ( $0.04 \%$ in R1; $0.04 \%$ in R2), just (0.03\% in R1; $0.01 \%$ in R2), mainly (0.01\% in R2), or (0.01\% in R1; $0.04 \%$ in R2), perhaps ( $0.08 \%$ in $\mathrm{R} 1 ; 0.01 \%$ in R2), probably $(0.1 \%$ in R1), secondly $(0.04 \%$ in R1), so (0.4\% in R1; $0.3 \%$ in R2), specifically ( $0.01 \%$ in R2), still ( $0.01 \%$ in $\mathrm{R} 2)$, then ( $0.02 \%$ in R1; $0.03 \%$ in R2), and usually ( $0.01 \%$ in $0.01 \%)$. As evident from Tables 2 and 3, there are several stylistically neutral DMs that appear both in R1 and R2. These DMs are also, and, as, but, if, however, just, or, perhaps, so, and then. The frequency of these DMs in R1 and R2, respectively, is exemplified by Figure 5 below. 


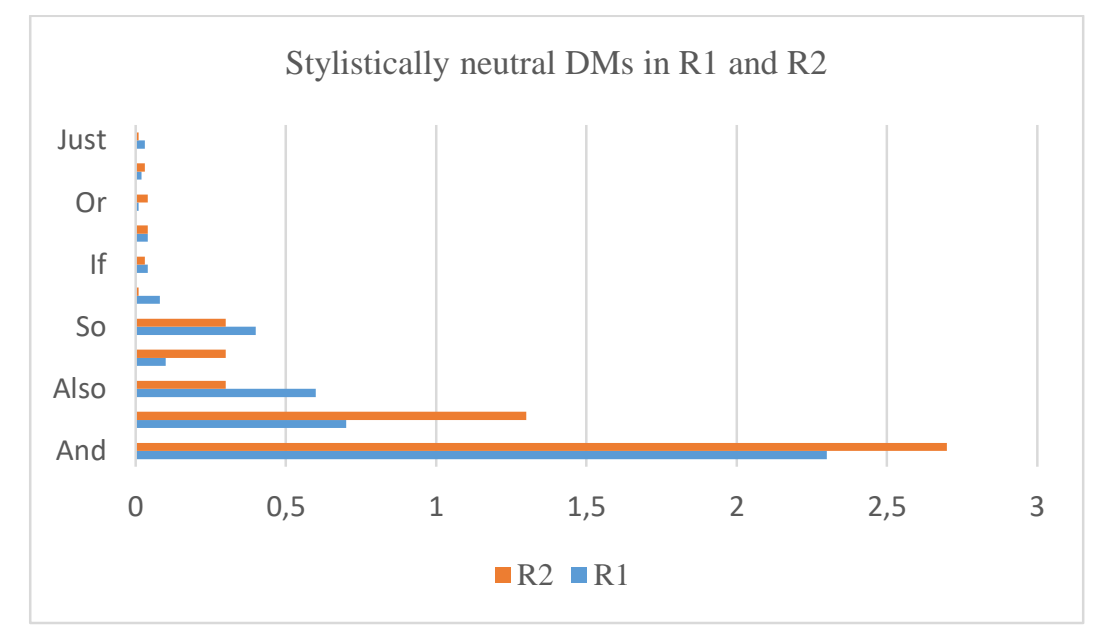

Figure 5. The frequency of stylistically neutral DMs in R1 and R2

It is seen in Figure 5 that the DMs also, and, as, but, if, however, just, or, perhaps, so, and then are similarly distributed in the corpus of the peer reviews. This observation is further supported by the paired sample t-test, which has been administered to the raw values of stylistically neutral DMs in R1 and R2. The results of the t-test reveal that there are no significant differences in the distribution of these DMs at $p<0.05, t(11)=1.07, \mathrm{p}=.31$. This finding is indicative of the similar use of the stylistically neutral DMs irrespective of the first or second rounds of peer reviews.

The formal DMs in the corpus of peer reviews are represented by the DMs further $(0.08 \%$ in $\mathrm{R} 1 ; 0.01 \%$ in R2), furthermore ( $0.01 \%$ in $\mathrm{R} 1 ; 0.01 \%$ in R2), rather ( $0.08 \%$ in R1) and subsequently $(0.04 \%$ in $\mathrm{R} 1)$. It should be noted that only two stylistically formal DMs are present both in R1 and R1, namely the DMs further and furthermore, whereas the formal DMs rather and subsequently are present in R1 and absent in R2. It is evident from the data that the formal DMs are less frequent in contrast to the stylistically neutral DMs.

The presence of the formal DMs concurrently with the absence of the informal DMs in the corpus of peer reviews is a novel finding in the present research. This finding is in contrast to the studies carried out by Šimčikaite (2012), Babanoğlu (2014), and Ziyagham \& Simin (2018), who point to the use of the informal DMs (e.g., wow, like, well, etc.) that are frequently used by EFL students in academic essays. Moreover, the results of the data analysis reveal that the present data are not characterised by register confusion in the sense posited by Šimčikaite (2012) and Babanoğlu (2014). There could be several reasons for the presence of the formal and neutral DMs in the corpus and the absence of the informal DMs. 
One of the reasons of the presence of the formal and neutral DMs in R1 and $\mathrm{R} 2$ could be related to the course teacher's suggestion to write the reviews in the formal register of English. Whilst it is possible to assume that the participants followed the instructions and produced peer reviews that conform to the formal register of academic writing in English, it should be reiterated that the process of peer review writing is not controlled in the study, i.e., the participants were given a suggestion to write the peer reviews in the formal style of English, however it was communicated to them that the peer review was not graded and that it was regarded as an internal writing task within the dyad of participants. It means that the participants enjoyed a substantial degree of freedom in terms of whether or not to follow the suggested instruction to use the formal register in peer review writing. However, the limited number and low frequency of the formal DMs in the study do not seem to indicate that the course teacher's suggestions are decisive in the participants' choice of DMs in peer reviews.

Another possible reason of the absence of informal DMs in the corpus of peer reviews could be explained by the practice effects associated with the writing process of academic essays. As previously mentioned in the article, two rounds of academic essays (E1 and E2) are required to be written in the formal register of the English language. Additionally, the participants are provided with the course teacher's detailed feedback on the essays in terms of the content, register and style in order to ensure that the participants' essays conform to the style of academic writing in English. Judging from the data presented in Tables 2 and 3, it appears reasonable to suggest that the participants' practice effects of writing two rounds of academic essays resulted in transferable writing skills in terms of the use of formal and neutral DMs whose use was applied by the participants to their peer review writing. Arguably, the practice effects in the form of repeated exposure (i.e., two rounds of essays) to the genre-appropriate standards of academic writing in English have resulted in the absence of the informal DMs in the corpus of the peer reviews.

\section{Conclusions}

The article presents a quantitative study that seeks to establish the frequency of DMs in the corpus of the participants' peer reviews of academic essays in EFL didactics. By means of applying the computer program WordSmith (Scott 2008) to the corpus of peer reviews and academic essays, the results of the study reveal the frequency of DMs in the corpus. It has been established that the most frequent DMs that are present both in the corpus of academic essays and peer reviews are also, and, as, but and so. These findings support the literature in EFL studies that discusses the frequent use of the DMs also, and, as, but and so by EFL student 
writers in academic writing in English (Chen 2006; Povolná 2013; Unaldi 2013; Gil 2018; Bax, Nakatsuhara \& Waller 2019). As far as the frequency of these DMs in the present corpus is concerned, I agree with Šimčikaite (2012) and Babanoğlu (2014), who argue that a relatively frequent use of the DMs also, and, $a s, b u t$ and so can be accounted by the frequent use of the analogous DMs in EFL student writers' L1. Given that the Norwegian equivalents of the English DMs also, and, as, but and so are reported to be frequently used in the Norwegian language (Westergaard et al. 2017; Johansen 2020), it is possible to conclude that the participants transfer the frequent DMs from their L1 to academic writing in English. Whilst this conclusion seems logical and finds support in the literature (Šimčikaitė 2012; Babanoğlu 2014; Gil 2018; Ziyagham \& Simin 2018), I would suggest conducting another study that involves written tasks both in English and Norwegian in order to examine the frequency of DMs in the parallel corpora.

Whilst the results of the present investigation appear to provide support to a number of previous studies (Chen 2006; Povolná 2013; Unaldi 2013; Gil 2018; Bax, Nakatsuhara \& Waller 2019), there is a novel finding that in contrast to the literature (Šimčikaitè 2012; Babanoğlu 2014; Gil 2018; Ziyagham \& Simin 2018). This finding is associated with the absence of informal DMs and the presence of formal and stylistically neutral DMs whose frequency is similar to that of academic essays. The latter observation is further supported by the results of the one-way analysis of variance (ANOVA) which reveal that the formal and stylistically neutral DMs are similarly distributed in the corpora. In addition, it is observed in the data that the frequency of stylistically neutral DMs exhibits a tendency to increase in R2 with the exception of the DMs also, just, or, and so that appear to be more frequent in R1.

Judging from these findings, it could be assumed that the participants' repertoire of DMs in the corpus of peer reviews converges on their choices of stylistically neutral DMs in academic essays. A possible explanation of the convergence and the subsequent prevalence of the stylistically neutral DMs could be offered by the practice effects. Specifically, repeated exposure to the formal requirements of academic essay writing in two rounds of essays (E1 and E2) taken in conjunction with the course teacher's feedback on the genre-appropriate standards of academic writing in English have resulted in the absence of the informal DMs in the corpus of the peer reviews. Obviously, this explanation is inconclusive, since the present study involves a limited number of participants $(\mathrm{N}$ $=12$ ) and relatively limited corpora (the total $\mathrm{N}$ of words in the corpus of essays $=27779$; the total $\mathrm{N}$ of words in the corpus of peer reviews $=4664$ ).

However, even within the limitations of the present study, it appears possible to formulate a number of linguo-didactic suggestions that might be relevant in EFL instructional contexts. First, it is suggested that the introduction of peer reviews in the course of academic writing could be beneficial to EFL student 
writers, who, according to Vorobel \& Kim (2014), could experience a dual role as a writer and a reviewer in the peer review dyad. Arguably, the duality of writer/reviewer roles might offer a certain sense of empowerment to EFL student writers, who would be exposed to getting constructive feedback concurrently with providing feedback as the reviewers in the dyad. Such a duality creates possibilities for EFL student writers to act as independent agents of change that might influence the process of essay writing in the dyad and, simultaneously, might get influenced by the dyad partner. The mutual flow of discursive influences might contribute to fostering the EFL student writers' metacognitive awareness of the genre-specific requirements in academic writing in English.

Second, from the linguo-didactic perspective, it seems pertinent to employ peer review writing as a means of facilitating and reinforcing practice effects of style-appropriate academic writing in English. Offering peer review writing to EFL student writers in the course of academic writing might provide additional opportunities to practice academic writing with the focus on style-appropriate discursive characteristics inclusive of such micro-discursive features as DMs and their style-appropriate use.

Finally, taking into consideration the present findings, the course in academic writing in English should involve a consideration of how micro-discursive features of the student writers' L1 should be compared with those in English. Specifically, I suggest drawing parallels between a corpus of DMs in the student writers' L1 and a respective corpus of DMs in English in order to facilitate EFL student writers' genre-appropriate use of DMs. Arguably, the juxtaposition of the DMs in the student writers' L1 and English would be especially beneficial in case of typological closeness between their L1 and English. Such a juxtaposition appears necessary in fostering positive and minimising negative transfer of DMs from the student writers' L1 to their academic writing in English.

\section{Acknowledgements}

The author of this article is appreciative of the participants in the study. The author is thankful to the editors and two anonymous reviewers, whose comments and suggestions are invaluable. 


\section{REFERENCES}

Aijmer, Karin. 2002. English discourse particles: Evidence from a corpus. John Benjamins.

Appel, Randy \& Andrzej Szeib. 2018. Linking adverbials in L2 English academic writing: L1-related differences. System 78. 115-129. DOI: 10.1016/j.system.2018.08.008

Babanoğlu, M. Pınar. 2014. A corpus-based study on the use of pragmatic markers as speech-like features in Turkish EFL learners' argumentative essays. Procedia. Social and Behavioral Sciences 136. 186-193. DOI: 10.1016/j.sbspro.2014.05.312

Bax, Stephen, Fumiyo Nakatsuhara \& Daniel Waller. 2019. Researching L2 writers' use of metadiscourse markers at intermediate and advanced levels. System 83. 79-95. DOI: $10.1016 /$ j.system.2019.02.010

Brusa, Maria Fernanda Poveda de \& Liliya Harutyunyan. 2019. Peer review: A tool to enhance the quality of academic written productions. English Language Teaching 12(5). 30-39. DOI: $10.5539 /$ elt.v12n5p30

Chen, Cheryl Wei-yu. 2006. The use of conjunctive adverbials in the academic papers of advanced Taiwanese EFL learners. International Journal of Corpus Linguistics 11(1). 113-130. DOI: $10.1075 / \mathrm{ijcl} .11 .1 .05 \mathrm{che}$

Connor, Ulla \& Anna Mauranen. 1999. Linguistic analysis of grant proposals: European Union research grants. English for Specific Purposes 18(1). 47-62. DOI: 10.1016/S08894906(97)00026-4

Conrad, Cheryl D., Liisa A. M. Galea, Yasukazu Kuroda \& Bruce S. McEwen. 1996. Chronic stress impairs rat spatial memory on the Y maze, and this effect is blocked by tianeptine treatment. Behavioral neuroscience 110(6). 1321-1334. DOI: $10.1037 / / 0735-7044.110 .6 .1321$

Council of Europe. 2011. Common European Framework of Reference for languages: Learning, teaching, assessment (CEFR). Language versions. Retrieved from http://www.coe.int/t/dg4/linguistic/cadreen.asp

Crawford, William J., Kim McDonough \& Nicole Brun-Mercer. 2019. Identifying linguistic markers of collaboration in second language peer Interaction: A lexico-grammatical approach. TESOL Quarterly 53(1). 180-207. DOI: 10.1002/tesq.477

Drew, Ion \& Bjørn Sørheim. 2016. English teaching strategies: Methods for English teachers of 10 to 16-year olds. Det Norske Samlaget.

Fish, Stanley. 2011. How to write a sentence: And how to read one. HarperCollins.

Fraser, Bruce. 1999. What are discourse markers? Journal of Pragmatics 31(7). 931-952. DOI: $10.1016 / \mathrm{S} 0378-2166(98) 00101-5$

Fraser, Bruce. 2015. The combining of Discourse Markers - A beginning. Journal of Pragmatics 86. 48-53. DOI: 10.1016/j.pragma.2015.06.007

Gil, Noelia Navarro. 2018. Reflexive metadiscourse in a corpus of Spanish bachelor dissertations in EFL. Research in Corpus Linguistics 6. 29-49. DOI: 10.32714/ricl.06.04

Hayisama, Faridah, Mohamed Ismail Ahamad Shah \& Wan Nur Asyura Wan Adnan. 2019. Rhetorical style across cultures: An analysis of metadiscourse markers in academic writing of Thai and Malaysian students. LSP International Journal 6(1). 19-37. DOI: $10.11113 /$ lspi.v6n1.76

Hryniuk, Katarzyna. 2018. Expressing authorial self in research articles written by Polish and English native-speaker writers: A corpus-based study. Studies in Second Language Learning and Teaching 8(3). 621-642. DOI: 10.14746/ssllt.2018.8.3.5 
Hu, Guangwei \& Sandra Tsui Eu Lam. 2010. Issues of cultural appropriateness and pedagogical efficacy: Exploring peer review in a second language writing class. Instructional Science 38. 371-394. DOI: 10.1007/s11251-008-9086-1

Hyland, Ken. 2008. Genre and academic writing in the disciplines. Language Teaching 41(4). $543-$ 562. DOI: $10.1017 / \mathrm{S} 0261444808005235$

IBM. 2016. SPSS Statistics for Windows, Version 24.0. IBM Corp.

Jančaříková, Renata, Renata Povolná, Olga Dontcheva-Navratilová, Světlana Hanušová \& Martin Němec. 2020. An academic writing needs analysis of Czech university graduate students. Discourse and Interaction 13(1). 42-66. DOI: 10.5817/DI2020-1-42

Jiang, Feng (Kevin) \& Ken Hyland. 2020. "There are significant differences...": The secret life of existential there in academic writing. Lingua 233. 102758. DOI: 10.1016/j.lingua.2019.102758

Joachim, Christian, Jim K. Gimzewski \& Arieh Aviram. 2000. Electronics using hybrid-molecular and mono-molecular devices. Nature 408. 541-548. DOI: 10.1038/35046000

Johansen, Stine Hulleberg. 2020. A contrastive approach to the types of hedging strategies used in Norwegian and English informal spoken conversations. Contrastive Pragmatics 2(1). 81-105. DOI: 10.1163/26660393-12340006

Kapranov, Oleksandr. 2017. Discourse markers in academic writing in EFL by Swedish pre-service secondary school teachers of English. Logos \& Littera 4(1). 21-39.

Kim, Sugene. 2019. Japanese student writers' perspectives on anonymous peer review. ELT Journal 73(3). 296-305. DOI: 10.1093/elt/ccy061

Kwon, Eunsook \& Shinhye Kim. 2019. Korean EFL college students' identity negotiation through peer review and revision in their writing. Studies in English Language and Literature 45(2). 237-263.

Lotfi, Seyyed Abdolmajid Tabatabaee, Seyyed Amir Hossein Sarkeshikian \& Elaheh Saleh. 2019. A cross-cultural study of the use of metadiscourse markers in argumentative essays by Iranian and Chinese EFL students. Cogent Arts \& Humanities 6(1). 1601540. DOI: $10.1080 / 23311983.2019 .1601540$

McDonough, Kim, Jindarat De Vleeschauwer \& William Crawford. 2018. Comparing the quality of collaborative writing, collaborative prewriting, and individual texts in a Thai EFL context. System 74. 109-120. DOI: 10.1016/j.system.2018.02.010

Mulligan, Adrian, Louise Hall \& Ellen Raphael. 2013. Peer review in a changing world: An international study measuring the attitudes of researchers. Journal of the American Society for Information Science and Technology 64(1). 132-161. DOI: $10.1002 /$ asi.22798

Paltridge, Brian. 2017. The discourse of peer review: Revieving submissions to academic journals. Palgrave Macmillan.

Povolná, Renata. 2013. On some variation in the use of discourse markers by Czech and German students of English. Discourse and Interaction 6(2). 41-60. DOI: 10.5817/DI2013-241

Ramos, Kathleen Ann. 2015. Using genre pedagogy to teach adolescent English learners to write academic persuasive essays. Journal of Education 195(2). 19-35. DOI: $10.1177 / 002205741519500205$

Sato, Shie. 2019. A corpus-based analysis of so in written discourse: A comparison between L1 English speakers and Japanese EFL learners. Applied Pragmatics 1(1). 26-45.

DOI: 10.1075/ap.00002.sat 
Scott, Mike. 2001. Comparing corpora and identifying key words, collocations, and frequency distributions through the Word Smith Tools suite of computer programs. In Mohsen Ghadessy, Alex Henry \& Robert L. Roseberry (eds.), Small corpus studies and ELT: Theory and practice, John Benjamins. 47-67. DOI: 10.1075/scl.5.07sco

Scott, Mike. 2008. Wordsmith Tools: version 4.0: single-user licence.

Šimčikaitè, Alè. 2012. Spoken discourse markers in learner academic writing. Kalbu Studijos 20. 27-34. DOI: $10.5755 /$ j01.sal.0.20.1196

Swales, John. 1990. Genre analysis: English in academic and research settings. Cambridge University Press.

Unaldi, Ihsan. 2013. Overuse of discourse markers in Turkish English as a foreign language (EFL) learners' writing: The case of 'I think' and 'in my opinion'. The Anthropologist 16(3). 575-584. DOI: 10.1080/09720073.2013.11891383

Vorobel, Oksana \& Deoksoon Kim. 2014. Focusing on content: Discourse in L2 peer review groups. TESOL Journal 5(4). 698-720. DOI: 10.1002/tesj.126

Westergaard, Marit, Natalia Mitrofanova, Roksolana Mykhaylyk \& Yulia Rodina. 2017. Crosslinguistic influence in the acquisition of a third language: The Linguistic Proximity Model. International Journal of Bilingualism 21(6). 666-682. DOI: $10.1177 / 1367006916648859$

Wolk, Christoph, Sandra Götz \& Katja Jäschke. 2021. Possibilities and drawbacks of using an online application for semi-automatic corpus analysis to investigate discourse markers and alternative fluency variables. Corpus Pragmatics 5. 7-36. DOI: 10.1007/s41701019-00072-x

Yallop, Roger Michael Alan \& Djuddah A. J. Leijen. 2018. The perceived effectiveness of written peer feedback comments within L2 English academic writing courses. Eesti Rakenduslingvistika Ühingu Aastaraamat 14. 247-271. DOI: 10.5128/ERYa14.15

Zhao, Huahiu. 2018. New insights into the process of peer review for EFL writing: A processoriented socio-cultural perspective. Learning and Instruction 58. 263-273. DOI: 10.1016/j.learninstruc.2018.07.010

Ziyagham, Faezeh \& Shahla Simin. 2018. Speech-like pragmatic markers in argumentative essays written by Iranian EFL students and native English-speaking students. International Journal of Foreign Language Teaching and Research 6(21). 133-145. 